\title{
Über die quantitative Bestimmung ätherischer öle.
}

\author{
Von
}

Martin Klassert.

Mitteilung aus dem Handelslaboratorium Dr. Wilhelm Hoepfoer in Hamburg.

[Eingegangen am 24. Dezember 1908.]

Zu der unter obigem Titel vor kurzem erschienenen Arbeit von R. Reich' möchte ich bemerken, daß der Autor in seiner ersten Versuchsreihe den Einfluß der Luftfeuchtigkeit leider nicht berücksichtigt hat.

Die in üblicher Weise isolierten ätherischen Öle enthalten, wenn man die Lösung, wie auf Seite 499 beschrieben, verdunsten läßt, kaum mehr wägbare Mengen Äther, dagegen je nach der Feuchtigkeit der Luft und der Menge des abgedunsteten Äthers stets eine mehr oder weniger beträchtliche Menge Wasser, und diesem Kondenswasser ist es im wesentlichen zuzuschreiben, wenr in der zweiter Spalte der Tabelle I (Seite 500) bei versehiedenen Ölen über 100\% der angewandten Substanz ausgewogen wurden.

Ohne nennenswerte Mehrarbeit und ohne Zeitverlust läßt sich die Lufufeuchtigkeit ausschalten, indem man die Verdunstung des Äthers in einem Strom getrockneter Luft vor sich gehen läßt; sehr bewährt hat sich bei meinen Bestimmungen ätherischer Ole folgende Anordnung:

Eine doppelt tubulierte Glocke (Fig. 20) wird mit ihrem oberen Tubus unter Zwischenschaltung einer kleinen U-Röhre mit Phosphorsäureanhydrid und Glaswolle mit einem Chlorcalciumtrockenturm verounden; in den unteren Tubus wird eine dreifach rechtwinkelig gebogene Glasröhre eingesetzt und diese nach Einschaltung einer trockenen Waschflasche und eines Blasenzählers mit der Wasserstrahlpumpe verbunden.

Das Gefäß mit der Ätherlösung setzt man unter

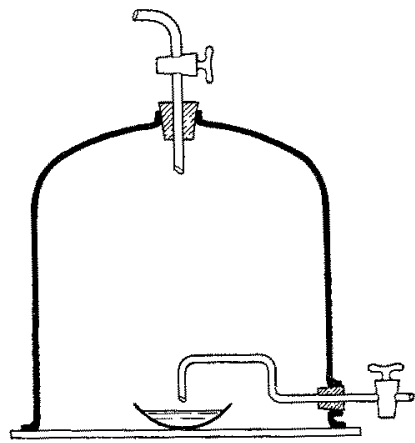

Fig, 20. die Glocke und zwar derart unter das nach unten gerichtete Ende der Glasröhre, daß die Mündung der Röhre etwa $1 \mathrm{~cm}$ von der Flüssigkeitsoberfläche entfernt ist. Regelt man dann den Luftstrom derartig, daß in der Minute etwa $40-60$ Blasen durch den Blasenzähler hindurchgehen, so verdampft der Äther sehr rasch; nach dem Beenden der lebhaften Verdunstung schliebt man die Luftzufuhr ab, läßt die Wasserstrahlpumpe etwa 2 Minuten voll wirken und schlieBt dann auch bier $a b$, läß das - nicht sehr grobe - Vakuum 5 Minuten wirken und bringt dann das meist noch stark abgekühlte Schälchen in einen gewöbnlichen Exsikkator zwecks Temperaturausgleichs; nach einer halben Stunde wägt man es.

Die Flüchtigkeit ätherischer Öle ist bei der niedrigen Temperatur, die während der kurzen Anwendung des Vakuums herrscht, verhältnismäbig gering; die übliche

1) Diese Zeitschrift 1908, 16, 497. 
längere Anwendung eines stärkeren Vakuums ist aber bier durch die Ausschaltung der Luftfeuchtigkeit völlig überflüssig.

Diese Notiz soll die Vorzüge des neuen von Reich abgeänderten Mann'schen Verfabrens nicht verkleinern; ich wollte nur darauf hinweisen, daß auch das seither übliche Verfahren unter Beobachtung besonderer Vorsichtsmaßregeln, wie ich sie oben geschildert habe, selbst bei schwierigen Objekten durchaus zufriedenstellende Ergebnisse liefert.

\section{Referate.}

\section{Butter, Speisefette und öle.}

W. Glikin: Über den Eisengehalt der Fette, Lipoide und Wachsarten. (Ber. Deutsch. Chem. Ges. 1908, 41, 910-915.) - Das Fett des Knochenmarkes verschiedener Tiere und Menschen, sämtliche Fette und Wachsarten tierischen und pflanzlichen Ursprungs sowie die Lipoide enthalten Eisen in organischer Bindung. Aus den ermittelten Zahlenwerten ist zu ersehen, daß das Knochenmark junger Tiere einen böheren Eisengehalt aufweist als das älterer, und zwar je jünger das Tier ist, desto mehr Eisen enthält es. So findet man z. B. beim neugeborenen Ferkel $1,15 \%$ Eisen, beim 6 Wochen alten Ferkel $0,3 \%$, beim 8 Wochen alten $0,15 \%$, beim alten Schwein im Mittel $0,03 \%$, beim neugeborenen Hund einen Wert von $4,35 \%$ (?), bei einem 5 Wochen alten $0,44 \%$, beim 10 -wöchigen $0,32 \%$, beim ausgewachsenen $0,05 \%$. Der Eisengehalt, des Knochenmarkes nimmt mit dem Wachstum des Tieres bezw. des Menschen $a b$ und zwar in demselben Verhältnis wie der Lecithingehalt, analog dem Eisengehalt der Leber, der bei neugeborenen Tieren etwa 10-mal so groß ist als bei ausgewachsenen. Die Frage, welcher Natur das in den Fetten und Wachsarten gefundene Eisen ist, kann jedoch nicht beantwortet werden. Der Versuch, das Eisen durch Schütteln mit salzsäurehaltigem Wasser zu entfernen, gelang nicht, man ist somit gezwungen anzunehmen, daß das Eisen im Fettmolekül in irgend einer festen Bindung enthalten ist. Auch im Lecithin und Cholesterin - den ständigen Begleitern der Fette konnte Eisen nachgewiesen werden. Ein aus Gehirn bergestelltes Lecithin enthielt $0,526 \%$ Eisen, Lecithinpräparate von Merk enthielten $0,3881 \%$ Eisen und $0,181 \%$ Eisen. Cholesterinpräparate von Kahlba um enthielten $0,06 \%$ Eisen und $0,03 \%$ Eisen. Doch können die Werte beim Lecithin und Cholesterin infolge allzugroßer Schwankungen noch nicht als endgültige betrachtet werden.

A. Hasterlik.

J. Lifschiitz: Eine Farben reaktion auf Cholesterin durch Oxydation. (Ber. Deutsch. Chem. Ges. 1908, 41, 252-255.) - Als Erkennungsmerkmal für Cholesterin verwendet Verf. die Farbenreaktionen, welche die ersten Oxydationsstufen des Cholesterins in Eisessiglösung auf Zusatz von konz. Schwefelsäure geben. Zur Oxydation eignen sich vorwiegend die Superoxyde der organischen Säureradikale, z. B. Benzoylsuperoxyd. Die Reaktion wird in folgender Weise ausgefïhrt: Einige Milligramm Cholesterin werden in $2-3 \mathrm{ccm}$ Eisessig gelöst und nach Zusatz einiger Körnchen Benzoylsuperoxyd 1-2-mal aufgekocht. In die abgekühlte Lösung gibt man 4 Tropfen konz. Schwefelsäure, welche sich am Boden des Reagensglases sofort blauviolett oder blaugrün färben. Das durelggeschüttelte Gemiseh färbt sich in kurzer Zeit entweder violettrot, bald darauf schön blau mit violettem Schein in durchfallendem Licht und erst nach langem Stehen rein grün; oder es nimmt nach dem Durchschütteln sofort eine grüne Farbe an, je nach der Menge des vorhandenen Benzoyl- 